\title{
Childhood Central Nervous System Embryonal Carcinoma
}

National Cancer Institute

\section{Source}

National Cancer Institute. Childhood Central Nervous System Embryonal Carcinoma. NCI

Thesaurus. Code C6208.

An embryonal carcinoma that arises from the central nervous system and occurs during childhood. 